\title{
POSSIBILITY AND IMAGINATION*
}

\author{
Alex Byrne \\ MIT
}

\section{Introduction}

Here is a familiar argument:

\section{Argument $\mathrm{K}$}

1. It is conceivable/imaginable that there is $\mathrm{C}$-fiber stimulation without pain.

2. If it is conceivable/imaginable that there is C-fiber stimulation without pain, then there could be C-fiber stimulation without pain.

3. If there could be $\mathrm{C}$-fiber stimulation without pain, pain is not identical to C-fiber stimulation.

Hence:

4. Pain is not identical to C-fiber stimulation.

In the argument's more recent and general dress, what is said to be conceivable/imaginable is that "zombies" exist (see, e.g., Chalmers 1996: 94-9), but let us concentrate on Argument K.

Descartes' case for the "real distinction" between mind and body arguably relies on a variant of Argument $\mathrm{K}$, where what is conceivable is mind without body, rather than body without mind. ${ }^{1}$ Kripke is widely supposed to have breathed new life into such "conceivability arguments".

Did he? The first claim of this paper is that he didn't. Argument $\mathrm{K}$ is not Kripke's; $\$ 2$ presents the evidence. But even if Argument $\mathrm{K}$ does not bear the Kripkean seal of approval, many others have been eager to endorse it, or to agree that it poses a serious challenge to physicalism. The second claim is that-at least under one interpretation of Argument $\mathrm{K}$ - they are wrong. Imaginability (in a natural sense to be explained in $\S 4)$ is no guide to possibility $(\$ 5,6,7)$.

Indulgently suppose all that's right: Kripke is no fan of Argument $\mathrm{K}$, and (with 'conceivable' read as 'imaginable') it is no good anyway. Still, Kripke 
undoubtedly argued against the identity theory — is his argument successful? The paper's third and final claim $(\S 8)$ is that it isn’t.

\section{Kripke}

On one standard interpretation, Argument $\mathrm{K}$ is the first part of Kripke's case against the identity theory in Naming and Necessity. Familiarly, in the second part, Kripke argues that the "apparent contingency" (1980: 150) between pain and C-fiber stimulation cannot be explained away-at least not on the model of the apparent contingency between heat and molecular motion. According to this standard interpretation, the second part of the argument attempts to rebut the following objection to premise 1: when we say we are imagining (Kripke does not use 'conceiving') that there is C-fiber stimulation without pain, we are misdescribing the content of the imagining. In Stoljar's terminology (2006: 74) we are suffering from "proposition confusion" - the real content of the imagining is some other proposition.

Is this interpretation correct? That is, is Kripke assuming that "imaginability" - whatever that is exactly - entails, or is at least a reliable sign of, (metaphysical) possibility? He can easily be interpreted that way. Of the table that (Kripke supposes) is essentially made from a certain block of wood, he says:

... though we can imagine making a table out of another block of wood or even from ice, identical in appearance with this one, and though we could have put it in this very position in the room, it seems to me that this is not to imagine this table as made of wood or ice, but rather it is to imagine another table, resembling this one in all external details, made of another block of wood, or even of ice. (1980: 114)

Looking at the table, I might say "I can imagine this very table as made of ice". And I might well say that, even though I am sure that the table is made of wood. Offhand, it seems pretty easy to imagine this table as made of ice. Is Kripke claiming that I have misidentified the content of my imagining, and that I am really imagining some table or other, resembling this one, as made of ice? That is a quite remarkable charge, requiring some supporting argument, and Kripke provides none; indeed, he shows no sign of recognizing that he is saying anything outlandish about the limits of imagination. Mistakes about the content of one's imaginings can happen, no doubt, but why would they happen when I am actually eyeballing the table itself, and presumably in the best possible position to imagine something about it? As Wittgenstein pointed out (1969: 39), we don't normally think that the attempt to imagine King's College on fire is a spotty, hit-or-miss affair, with the imagination often only connecting with the proposition that some similar building is on fire.

On the interpretation of Kripke we are considering - close to the "Textbook Kripkeanism" of Yablo $2000^{2}$ — he does think of the imagination as rather like 
the "telescope" for viewing other possible worlds that he disparages in the first lecture (1980: 44). One dimly glimpses through the fog of one's imagination a genuinely possible situation in which there is a table made of ice. Is it this very table or not? After all, it looks very much like this table! No, Kripke is said to reply, it is merely a dead-ringer for this table. Needless to say, this interpretation fits poorly with Kripke's dismissal of the question "how can I identify this table in another possible world"? (52). Don't even ask, he says: "I have the table in my hands, I can point to it, and when I ask whether it might have been in another room, I am talking, by definition, about it" (52-3).

However, it is easy to cite further passages, in which Kripke seems to be declaring that we can't imagine one or another impossibility. We can't "imagine a situation in which it would have happened that this very woman [the Queen] came out of Mr. and Mrs. Truman" (112); "whatever we imagine counterfactually having happened to [this object here]...the one thing we cannot imagine happening to this thing is that it, given that it is composed of molecules, should still have existed and not have been composed of molecules" (127); "supposing Nixon is in fact a human being, it would seem that we cannot think ['imagine' is used two sentences earlier] of a possible counterfactual situation in which he was, say, an inanimate object" (46).

However, this apparent support for the standard interpretation looks considerably weaker on closer examination. Throughout Naming and Necessity, Kripke uses 'possible world' and 'counterfactual situation' pretty much interchangeably, and when he speaks simply of "situations" it is usually clear that these are "counterfactual situations"; that is, talk of situations is talk of what could have been the case (see, e.g., 130). ${ }^{3}$ There is no "situation" in which Kripke squares the circle, for example. So, when Kripke says that we can't imagine a situation in which the Queen is the biological daughter of Mr. and Mrs. Truman, 'imagine' could easily be otiose: we can't imagine (or "think of") such a situation, not because of limits to our imagination, but because there is no such situation to imagine.

(Compare: "I can't imagine a philosopher who would do this", said when discovering Smith's foully murdered corpse in the departmental library. In the right sort of context, such an utterance would be primarily intended to convey the proposition that the murderer was not a philosopher, and/or that this is the speaker's opinion. And if the utterance is so intended, the scope and limits of imagination are completely beside the point: presumably one can imagine Stalnaker having a murderous disposition, and one can certainly imagine $a$ philosopher who would do this, with 'imagine' taking wide scope.)

The other passages can be read in a similar way: when Kripke says that we cannot "imagine counterfactually" (my emphasis) that this object is not composed of molecules, he may be reasonably read as saying that we can't imagine a "counterfactual situation" in which this object is not composed of molecules; and this may in turn be interpreted as the claim there is no counterfactual situation in which this object is not composed of molecules. Likewise for the 
quotation about Nixon, where Kripke says that "we cannot think of a possible counterfactual situation" in which Nixon is inanimate - we can't "think of" such a possible situation in the sense that we can't "think of" a highest prime.

The following passage from "Identity and Necessity" might seem more recalcitrant ${ }^{4}$ :

[The statement] "Pain is in general is such and such a neural (brain) state." .. is held to be contingent on the following grounds. First, we can imagine the brain state existing though there is no pain at all. It is only a scientific fact that whenever we are in a certain brain state we have a pain. Second, one might imagine a creature being in pain, but not being in any specified brain state at all, maybe not having a brain at all... So it seems that we can imagine definite circumstances under which [or "a situation in which"] this relationship would have been false. (Kripke 1977: 98, my italics)

If Kripke had said that the "grounds" were simply that we can imagine a situation in which the identity fails to hold, then this would have strongly supported the standard interpretation. For suppose, against the standard interpretation, that Kripke's 'we can imagine a situation in which p' amounts to 'the proposition that $\mathrm{p}$ could have been true'. Then Kripke would have been saying-at best pointlessly - that the identity is contingent on the grounds that it is contingent.

However, Kripke's grounds are much more specific: we can imagine the brain state without the pain, and imagine a brainless creature in pain. And that is perfectly consistent with the redundancy of 'imagination'. It is not trivial or confused to say that the identity is contingent because someone could have been in the brain state without being in pain, or that someone could have been in pain without having a brain: neither of these two "grounds" is equivalent to the claim that they are said to ground.

What's more, the standard interpretation runs into trouble with Kripke's later remark that "the materialist ... has to hold that we are under some illusion in thinking we can imagine that there could have been pains without brain states" (100-1, my italics). On the standard interpretation, Kripke is in effect saying that the materialist, faced with Argument K, must deny the first premise, that we can imagine a situation in which there are pains without brain states (or, in our version of the argument, C-fiber stimulation without pain). But an obvious response to Argument $\mathrm{K}$ - and perhaps the most popular - is to deny the second premise, that if such a situation is imaginable, it is possible. If Kripke had overlooked this response he would have made a serious mistake. I rest my case. $^{5}$

On the suggested interpretation, Kripke is not offering any epistemology of modality at all. ${ }^{6} \mathrm{He}$ is simply making various claims about what could and couldn't have been the case, which strike him as intuitively correct. Whether they strike him as correct because of the exercise of a faculty of "imagination", or for some other reason, is left open. Since Kripke says again and again that we cannot 
"imagine" one or another impossibility, arguably the only alternative interpretation has him maintaining that imaginability entails possibility (see also the previous paragraph). It is scarcely credible that Kripke would assume such a strong thesis without argument or even any sort of explicit comment, while remaining entirely silent on what "imagination" is supposed to be. And, perhaps more importantly, for Kripke's purposes an epistemology of modality is completely unnecessary: most of us will agree — at least at first glance — that there could have been $\mathrm{C}$-fiber stimulation without pain, and this is all that Kripke needs.

Kripke will reappear at the end. Meantime: is imaginability a guide to possibility?

\section{Imaginability as a "guide"}

Postpone the question of what "imaginability" might be. What is it for imaginability to be a "guide to possibility"?

Propositions are the sorts of things that are possible or impossible; the sorts of things that are "imaginable", in the sense relevant to Argument K, therefore must include propositions. So the slogan that "imaginability is a guide to possibility" can be partly unpacked as follows: $p$ 's imaginability is a guide to $p$ 's possibility. ${ }^{7}$ But what does that mean?

Clearly what is intended is (at least) something along these (impressionistic) lines: generally, if $p$ is imaginable, $p$ is possible. ${ }^{8}$ Fortunately, in the present context we can get by with a necessary condition for imaginability to be a guide to possibility.

Nixon, we may fairly assume, could have been an accountant, or could have been impeached, or could have lost to Humphrey. But could he have been a poached egg? Let a "Kripkean impossibility" be a proposition explicitly certified as impossible in Naming and Necessity: that this table is made of ice, that Nixon is inanimate, that the Queen is a Truman, etc. ${ }^{9}$ Most participants in the debate about imaginability (or conceivability) and possibility are prepared to grant, if only for the sake of the argument, that "Kripkean impossibilities" are genuinely impossible; we may follow them in this.

Now, according to a proponent of the Smart/Place identity theory (informed by the lessons of Naming and Necessity), the identification of pain with C-fiber stimulation is necessary and a posteriori. Suppose that some Kripkean impossibilities are imaginable - that Nixon is inanimate, say. There is nothing particularly mind-boggling about Kripkean impossibilities in general, and nothing about this proposition in particular: it predicates a familiar property of a familiar individual. The proposition that there is C-fiber stimulation without pain is not as quotidian: it is not immediately clear what "stimulation" is supposed to be, and anyway Kripke himself confesses that he knows "virtually nothing about C-fibers" (Kripke 1980: 149). ${ }^{10}$

If it is imaginable that Nixon is inanimate, then presumably the faculty of imagination is unreliable as an indicator of possibility. (Similarly, if in daylight 


\section{0 / Alex Byrne}

conditions, and facing an ordinary scene, one seems to see flying pigs, one's vision is unreliable as an indicator of actuality.) If some Kripkean impossibilities are imaginable, then the imaginability of C-fiber stimulation without pain will be little cause for concern. So, in the present context, "imaginability is a guide to possibility" only if Kripkean impossibilities are unimaginable. But this necessary condition needs a little clarification.

Those who think that imaginability is a guide to possibility contrast it with entertaining, supposing, or assuming. Granted that Nixon is essentially human (and so not inanimate), we may readily entertain, suppose or assume the impossible proposition that he is inanimate. And this capacity is not at all affected by empirical discoveries, in particular, the discovery that Nixon is in fact human.

If imaginability is a guide to possibility, that Nixon is inanimate should not be imaginable. But there are two ways this might work. First, it might be unimaginable, even before doing any empirical investigation, that Nixon is inanimate. Second - and perhaps more plausibly - that proposition might start out as imaginable but turn unimaginable once the empirical information about Nixon's biology comes in.

\section{Imagining and conceiving}

Return to the first premise of Argument K:

1. It is conceivable/imaginable that there is C-fiber stimulation without pain.

So far (following Kripke) the discussion has been conducted using 'imaginable', rather than 'conceivable', although in the recent literature the latter term is generally preferred over the former. In the relevant sense, what is it to "conceive" or "imagine" that there is C-fiber stimulation without pain?

The question is especially pressing because 'imagine' can be used to mean suppose, and both 'conceive' and 'imagine' can be used to mean entertain or think of. So, since we can suppose, assume, consider, entertain or think of the hypothesis that there is $\mathrm{C}$-fiber stimulation without pain, on one straightforward reading we can imagine or conceive of impossibilities. Confusingly, in another sense possibilities are unimaginable or inconceivable. "It is unimaginable/inconceivable that Fred is the murderer", one might say, taking Fred's lack of motive and cast-iron alibi to be overwhelming evidence against his guilt; one is not denying that the hypothesis could have been true. Here one means that the hypothesis is not credible or believable (see Van Cleve 1983: 36, Yablo 1993: 7-8 and Tidman 1994: 302-3).

In ordinary talk, to imagine $p$ (that there are tailless kangaroos, say) in one sense requires more than merely entertaining $p$. Something extra is needed: a 
mental image of a tailless kangaroo is sufficient - and perhaps it is also necessary. Is this sense of 'imagine' the appropriate one for interpreting Argument K?

That depends whom you ask. Hume's famous "establish'd maxim", in one of its formulations, is "that nothing we imagine is absolutely impossible" (1740/1978: 32); here Hume is not using 'imagine' in some special technical sense. And neither, presumably, is Kripke; hence on the standard interpretation discussed earlier he is in rough agreement with Hume. More recently, Hart defends the view that "[w] hat [a person] imagines is possible" (1988: 23), and he makes it clear that the relevant kind of "sensuous imagination" (15) is supposed to be familiar to us all: "There are no purple polar bears, but each of us is convinced that there could have been, and what convinces us is that we can visualize a polar bear dyed purple" (30).

A more nuanced version of this sort of view is in the famous footnote to "What is it like to be a bat?":

A theory that explained how the mind-brain relation was necessary would still leave us with Kripke's problem of explaining why it nevertheless appears contingent. That difficulty seems to me surmountable, in the following way. We may imagine something by representing it to ourselves either perceptually, sympathetically, or symbolically... To imagine something perceptually, we put ourselves in a conscious state resembling the state we would be in if we perceived it. To imagine something sympathetically, we put ourselves in a conscious state resembling the thing itself... Where the imagination of physical features is perceptual and the imagination of mental features is sympathetic, it appears to us that we can imagine any experience occurring without its associated brain state, and vice versa. The relation between them will appear contingent even if it is necessary, because of the independence of the disparate types of imagination. (Nagel 1974: 446, fn. 11).

Notice that Nagel implicitly interprets Kripke as tracing the apparent contingency between experiences and brain states to the fact that we can (sensuously) imagine one without the other. In response, Nagel in effect draws a distinction between two types of sensuous imagination, perceptual and sympathetic, and tries to argue that when an act of sensuous imagination combines the two types (as when we imagine C-fiber stimulation without pain), it is no guide to possibility, thus denying the second premise of Argument K. ${ }^{11}$

Chalmers provides another example:

Positive notions of conceivability require that one can form some sort of positive conception of a situation in which [statement] $\mathrm{S}$ is the case. One can place the varieties of positive conceivability under the broad rubric of imagination: to positively conceive of a situation is to imagine (in some sense) a specific configuration of objects and properties. (2002: 150)

'Modal Imagination' (another term for "positive conceivability"), Chalmers says, "is used here as a label for a certain sort of familiar mental act. Like other 


\section{2 / Alex Byrne}

such categories, it resists straightforward definition. But its phenomenology is familiar" (151). That sounds like Hart's "sensuous imagination", but Chalmers takes it to be broader. One can, he says, positively conceive of a situation in which S is the case (say, "Germany winning the Second World War") without "form[ing] a perceptual image that represents $S$ " (151).

Taking Argument K's talk of "imaginability/conceivability" to fall under "the broad rubric of imagination" has some prominent supporters, then. On the other hand, the fact that 'conceive' is usually the term of choice suggests that conceivability arguments do not simply appropriate a state or activity from folk psychology. In contexts like Argument K, 'conceive' has something of a technical flavor, at best loosely related to common understandings of the word. Yablo, for instance, speaks of "philosophical conceivability" (1993: 7), or conceivability in "the philosopher's sense" (12). ${ }^{12}$ And Chalmers defines "negative conceivability' in terms of a priori knowledge. Simplifying his terminology slightly, "S is . . negatively conceivable when it is not a priori that $\sim S$ " (2002: 149)..$^{13}$

Clearly there are many ways of interpreting Argument K. However, if the relevant kind of "conceiving/imagining" is not a familiar mental state or activity, for which 'imagining' or 'conceiving' is at least a reasonable label ("negative conceivability" might be held open to this charge), perhaps one should follow Bealer and proclaim that "talk of conceivability and [imaginability] is an idle complication that only breeds confusion" (2002: 76).

In any event, not all interpretations can be considered here. So let us restrict attention to straightforward "Humean" interpretations of 'conceiving/imagining': Hart's sensuously imagining, and Chalmers' positively conceiving. And since negatively conceiving is being passed over, so is "twodimensionalism". 14

\section{The perceptual analogy}

Imagining is often understood on the model of Kripke's telescope for viewing other possible worlds. That is, imagining stands to possibility as perceiving stands to actuality. Thus Hart, for example:

...the leading analogy of [an epistemology of modality] is that imagination is to knowledge of nonactual possibility as perception is to knowledge of actuality. (1988: 23)

It is worth noting that if this is right, then Argument $\mathrm{K}$ is (arguably) misleadingly set out. The premises of an argument should exhibit evidence for its conclusion. One may come to know that there is a pig in the yard by seeing buckets of pig food, and catching a porcine whiff. Visual and olfactory perception are the source of one's evidence, the means by which one acquires one's evidence. One's 
evidence is that there are buckets of pigfood, and a porcine odor; it does not (or need not) include the fact that one sees buckets of pigfood, that something looks to be a bucket of pig food, and the like. One may know that there is a pig in the yard by seeing and smelling, without any perceptual facts being part of one's evidence. (Perky the pig might know, by seeing and smelling, that Pinky the pig is present, without Perky having any conception of his own perceptual states.)

If that is correct, and if imagining is like perceiving, then Argument $\mathrm{K}$ is better reformulated as follows:

\section{Argument $\mathrm{K}^{*}$}

$1^{*}$. There could be $\mathrm{C}$-fiber stimulation without pain. $\dagger$

$2^{*}$. If there could be $\mathrm{C}$-fiber stimulation without pain, pain is not identical to C-fiber stimulation.

Hence:

3*. Pain is not identical to C-fiber stimulation.

$\dagger$ Note: the way in which we know premise $1^{*}$ is by sensuously imagining C-fiber stimulation without pain. ${ }^{15}$

But is the perceptual analogy apt? One disanalogy, of course, is that perception involves a kind of causal process that imagining doesn't. When one sees an actual mute donkey there is a causal process starting with light reflecting from the donkey and then proceeding to the eye and into the brain. This is not a good model for imagining a merely possible talking donkey. Mere possibiliacontroversially granting that there are such things - have no actual effects. And in any case, one may presumably imagine a talking donkey without there being a particular possible talking donkey that one is imagining.

If the perceptual analogy is to be any use at all, imagining, like perceiving, must involve appearances. And as soon as appearances are on the scene, illusion is not far behind: sometimes $p$ characterizes how things visually appear (that one line is longer than another, that one patch is brighter than another, that a spot is moving, etc.) even though $p$ is false. Are there modal illusions as there are visual illusions?

Even if one is firmly convinced that the two lines are equal, that the patches are equiluminous, that the spot isn't moving, the appearance to the contrary will persist. A modal illusion, properly so-called, would require the appearance that $p$ is possible in the presence of the conviction that $p$ is impossible.

Suppose one sensuously imagines a purple polar bear-specifically, one "visualize[s] [a] polar bear dyed purple", as Hart puts it. This is "objectual" imagining: one imagines, not just that there is a purple polar bear, but (to put it loosely and intuitively) a specific witness for that existential claim. (For helpful discussion, see Yablo 1993: 27.) Still, one's objectual imagining has propositional content: the bear is imagined as (dyed) purple, as a bear, as sitting on an ice floe, say. That is, various propositions are true of the imagined situation: that purple polar bears exist, for instance. 


\section{4 / Alex Byrne}

So what one imagines, inter alia, is that purple polar bears exist; one does not merely imagine that purple polar bears could have existed. And this is not in dispute, least of all by Hart. The gloss on premise $1^{*}$ of Argument $\mathrm{K}^{*}$ presupposes this consensus: we sensuously imagine that there is $\mathrm{C}$-fiber stimulation without pain, not (merely) that there could have been $\mathrm{C}$-fiber stimulation without pain. (More generally, it has been assumed from the start that whatever "imagining/conceiving" is, if it is a guide to possibility, then we can know that such-and-such could have been the case by imagining/conceiving such-and-such being the case.)

The problem is that this makes sensuous imagining too much like perceiving. The content of perception is that various conditions in fact obtain - that the lines are the same length, that there are white polar bears, and so on-not merely that there could have been lines of the same length, or that there could have been white polar bears. If sensuous imagination stands to possible worlds as perception stands to the actual world, then the content of sensuous imagination should concern possibility, not actuality. Then, just as perception involves the appearance of actuality, sensuous imagination would involve the appearance of possibility.

But that's not right: if sensuous imagination involves the appearance of anything, it's the appearance of actuality, not possibility. What "appears to be so", when one imagines a purple polar bear, is that purple polar bears exist, not (merely) that they could have existed. (Of course, one will not believe that things are as they appear.) If reinforcement of this claim is needed, the "Perky effect"mistaking perception for sensuous imagination-will do. If imagining a yellow banana (say) merely involves the appearance that yellow bananas are possible, why would subjects take themselves - as they do in Perky-style experiments - to be (only) imagining a yellow banana when they are in fact seeing one? ${ }^{16}$

The same points hold for Chalmers' positive conceivability (of which sensuous imaginability is supposed to be a special case). There are no appearances of possibility in a way that would support the perceptual analogy; that analogy is therefore best dropped.

\section{Sensuously imagining}

Although sensuous imagination is not a faculty for perceiving possible worlds, it might still be insisted that sensuously imagining $p$ is (somehow) a guide to $p$ 's possibility. After all, Hart's claim that "what convinces us" that there could have been purple polar bears "is that we can visualize a polar bear dyed purple", surely has a ring of plausibility to it.

Visualizing is a special case of sensuously imagining. One may also sensuously imagine auditorily and kinesthetically; the existence of other kinds of sensuous imagination - tactile, gustatory, olfactory, and so on - is less obvious. ${ }^{17}$

Visualizing a tiger is similar to seeing a tiger; auditorily imagining clashing cymbals is similar to hearing clashing cymbals, and so on. Why is that? The 
received view, supported by various lines of converging evidence, is that visualizing a tiger (for example) involves "visual representations"-mental representations that are proprietary to the sense of sight; likewise for auditorily imagining clashing cymbals. Since a "visual representation" is supposed to represent a distinctively visual package of information (or misinformation), this purported similarity between visualizing and seeing is, in part, a similarity in the contents of the representations, not merely a similarity between the representations themselves. When one visualizes a tiger, one is in a state with a distinctively visual content, a pared-down version of the content of the state of seeing a tiger. (More exactly: seeing a perfectly ordinary tiger in good light.) That is why, like vision, visual imagination has an "objectual character". ${ }^{18}$

One dispute about visual imagery - often called 'the imagery debate' concerns the nature of the "visual representations" that are supposed to underlie both seeing and visualizing. Are they more like pictures or more like sentences? Since this dispute seems to have no bearing on whether visualizing, or sensuous imagination generally, is a guide to possibility, we may set it aside here. ${ }^{19}$

The imagery debate is to a large extent a debate within cognitive psychology, although of course philosophers have occasionally stuck in their oars. Another debate-more-or-less exclusively philosophical-concerns the vexed matter of "qualia". Put both roughly and in specialized jargon: is the phenomenal character of perception and sensuous imagination entirely determined by their distinctive content, or is it partly due to non-representational properties-"qualia" - of these mental states or events? Again, this dispute seems to be irrelevant to the question at hand. The presence or absence of qualia makes no difference to whether sensuous imagination is a guide to possibility.

We may therefore set aside the imagery debate and the issue of qualia. Recalling the discussion in $\$ 2$, sensuous imagination is a "guide to possibility" only if Kripkean impossibilities are not readily sensuously imaginable.

The argument will be, first, that one can "seem to perceive", or perceptually experience, Kripkean impossibilities. 'Seem to perceive' is to be understood in a familiar sense: for example if one sees someone crossing the street and misidentifies her as Judy one "seems to perceive" that Judy is crossing the street. Second, given the received view about the close kinship between perception and imagination, this supports the intuitive claim that one can sensuously imagine Kripkean impossibilities, even in the face of the relevant empirical facts.

There are familiar examples of perceptual experience that are apparently of impossibilities. In the waterfall illusion, the rocks look both to be moving and not moving; in the barber pole illusion one hears a sound as continually increasing (or decreasing) in pitch yet not getting any higher (or lower); in certain conditions one can see something as reddish-green; Escher-style "impossible objects" provide another range of examples. ${ }^{20}$

These impossibility illusions are, in some intuitive sense, strictly perceptual. Presumably one will not believe that the rocks are both moving and not moving; yet that is still the way they look. Moving beyond strictly perceptual illusions, 
into the more belief-infected kind of perception, we can find other examples of perceptually experiencing impossibilities.

Suppose one is familiar with the daughter of Mr. and Mrs. Truman. In fact, she and Queen Elizabeth look remarkably alike. Seeing the Queen on the street, one misidentifies her (by sight) as the daughter of Mr. and Mrs. Truman. One sees her as the Truman's daughter; "I saw the Trumans' daughter on the street and recognized her immediately", one might say. What one seemed to perceive, namely that that woman is the Truman's daughter, is impossible.

Similarly, suppose sees a certain table (in fact made of wood, but covered with frost), at an ice sculpture exhibition. One takes it to be made of ice: "I looked at the table and clearly saw it was made of ice", one might say. What one seemed to perceive, namely that that table is made of ice, is impossible.

The content of sensuous imagination is not restricted to simple arrangements of shapes, colors, sounds, and so on: that a small red ball is on top of a large blue cube, for instance. We can also sensuously imagine that King's College is on fire, that a tiger is stalking the Queen, that Nixon is inanimate, and so on. Given the examples in the previous two paragraphs, and the received view of the kinship between perception and imagination, there is no evident reason to deny that one can sensuously imagine Kripkean impossibilities: that the Queen is a Truman, that this table is made of ice, that Nixon is inanimate, and so on. ${ }^{21}$ And, on the face of it, knowledge of the empirical facts - that this table is made of wood, say-makes no difference. Learning empirical facts does not typically limit one's imaginings: learning that the elephant-sized spiders of various B-movies would collapse under their own weight does not make it harder to imagine them laying waste to our cities. So why suppose learning that the table is made of wood will disrupt one's prior imagining of the table as made of ice? An argument is needed, and none has been offered. All this falls short, of course, of establishing that Kripkean impossibilities are imaginable, but it does provide some reinforcement to naïve first impressions.

If it is a mistake to think that sensuous imagination is a guide to possibility, why is this mistake often made? Part of the answer-although no doubt not the whole story - is that sensuous imagination is intimately involved in reasoning about possibilities, albeit not in the way philosophers have taken it to be. One can use sensuous imagination, appropriately constrained by empirical knowledge, to find out what would have been the case if things had gone slightly differently. Could we have hauled the piano upstairs, instead of taking it in through the window? One might answer that question - indeed, one might come to know the answer - by imagining the piano being manipulated around the winding staircase. (Just why mental imagery is useful in this way is poorly understood.) ${ }^{22}$ But this highly empirically constrained role for imagination is quite compatible with imagination in general ranging far and wide over impossibilities. Undisciplined by concern for the empirical facts, one may imagine the piano being made of ice, being the offspring of Mr. and Mrs. Truman, turning into a butterfly and flying up the stairs, or whatever. 


\section{Positive conceivability}

Sensuous imagination is a doubtful guide to possibility; the other Humean candidate is positive conceivability. Is that any better?

One immediate problem is that Chalmers takes sensuous imagining to be a species of positive conceiving: if Kripkean impossibilities may readily be sensuously imagined, then this at least partly impugns positive conceivability in general. But perhaps the real guide to possibility is the kind of positive conceiving that isn't also sensuous imagining - that is not "grounded in imagery" (Chalmers 2002: 151). What is that kind of positive conceiving? Here is Chalmers' explanation:

There is a sense in which we can imagine situations that do not seem to be potential contents of perceptual experiences. One can imagine situations beyond the scale of perception: e.g.... Germany winning the Second World War...

In these cases, we do not form a perceptual image that represents $\mathrm{S}$. Nevertheless, we do more than merely suppose that $\mathrm{S}$, or entertain the hypothesis that $\mathrm{S}$. Our relation to $\mathrm{S}$ has a mediated objectual character that is analogous to that found in the case of perceptual imaginability. In this case, we have an intuition of (or as of) a world in which S, or at least of (or as of) a situation in which $\mathrm{S}$, where a situation is (roughly) a configuration of objects and properties within a world. We might say that in these cases, one can modally imagine that $\mathrm{P}$. One modally imagines that $\mathrm{P}$ if one modally imagines a world that verifies $\mathrm{P}$, or a situation that verifies $\mathrm{P}$. Modal imagination goes beyond perceptual imagination, for the reasons above, but it shares with perceptual imagination its mediated objectual character.

... To modally imagine Germany winning the Second World War, one might imagine a world in which certain German armies win certain battles and go on to overwhelm Allied forces within Europe. When one reflects on these imagined (parts of) worlds, they reveal themselves as (parts of) worlds in which... Germany won the Second World War. (151)

Germany's winning the Second World War is not the sort of thing one might straightforwardly perceive, in the way that one can perceive a red ball's being on top of a blue cube. One can't see Germany - at least not in the way one can see the red ball or the blue cube. And the property of winning the Second World War is not a perceptible property - at least not in the way redness or sphericity are perceptible properties. But that doesn't mean that one can't perceive (in a genuine "perceptual" sense) that Germany has won the Second World War. There is a continuum of perceptual cases, starting with the most low-level, noninferential, and cognitively impenetrable, and ending with the highly theory-laden and inferential. Gazing towards Buckingham Palace, one sees something moving. One sees that someone is waving; one sees that Hitler is waving from the Palace balcony; one sees that the Wehrmacht has taken control of London; one sees that Germany has won the Second World War. 


\section{8 / Alex Byrne}

And - as one might expect - there is corresponding continuum for imagination, starting with cases where the "sensory core" of the imagining, in some intuitive sense, determines the imagined content, and proceeding through cases where the sensory core becomes less and less important. ${ }^{23}$ If it is admitted that one can sensuously imagine that Hitler is waving from the Palace balcony, there is no point denying that one can sensuously imagine that Germany has won the Second World War: the difference is of degree, not kind. Modal imagination and sensuous imagination are one and the same. ${ }^{24}$

\section{Kripke revisited}

Finally, back to Kripke's own argument, which (on the present interpretation) is Argument $\mathrm{K}^{*}$ of $\S 4$, minus the gloss on the source of justification for premise $1^{*}$ :

\section{Argument $\mathrm{K}^{*}$}

$1^{*}$. There could be $\mathrm{C}$-fiber stimulation without pain.

$2^{*}$. If there could be $\mathrm{C}$-fiber stimulation without pain, pain is not identical to C-fiber stimulation:

$3^{*}$. Pain is not identical to C-fiber stimulation.

For the reasons given in $\S 2$, Kripke does not argue for the first premise, or trace its epistemic status to the operation of his faculty of imagination. He just points out, not unreasonably, that "the correspondence between a brain state and a mental state seems to have a certain obvious element of contingency" (1980: 154).

In his classic paper arguing for the identity theory, Smart's chief example is the identification of having a "yellowish-orange after-image" with "a certain sort of brain-process". "Objection 4" runs as follows:

The after-image is not in physical space. The brain-process is. So the after-image is not a brain-process. (Smart 1959: 150)

Smart replies that this is an "ignoratio elenchi. I am not arguing that the afterimage is a brain process, but that the experience of having an after-image is a brain process" (65).

When one enjoys the "experience of having an yellowish-orange afterimage", plausibly one is only (ostensibly) aware of the after-image, the (apparent) object of the experience. One is not aware of the experience itself, the mental event or process that Smart identifies with a brain-process. These and related points comprise the so-called "transparency" of experience (see, e.g., Tye 2003: 22-4). And once transparency is granted, the very existence of the experience is in considerable doubt. Of course, one seems to see a yellowish-orange patch, but why suppose this involves the occurrence of a mental event? Perhaps it looks 
to one that an event is occuring - the afterimage is shimmering slightly, say. However, that event is not the alleged experience, any more than the afterimage is.

In the case of after-images, two things can be distinguished-an ostensible particular and an instantiated psychological property. The particular is the yellowish-orange after-image itself-although, as Smart points out (1959: 151), there is no such item. The property is seeming to see a yellowish-orange afterimage. ${ }^{25}$ Introspection doesn't reveal that there is, in addition, a mental event or happening, one's "experience of the after-image". So why think there is such a thing? (For an extended discussion of the nonexistence of "experiences", see Byrne forthcoming.)

For reasons that are not entirely clear, in the case of pain these points are apt to seem considerably less compelling. But pain is no different: when one has a stabbing pain in one's elbow, the only apparent event in the vicinity is the pulsating unpleasant disturbance in the elbow-more cautiously, that appears to be in the elbow. One does, of course, have the property of being aware (or, more cautiously, of seeming to be aware) that this event is occuring, but again it is unclear why this involves the occurrence of a mental event, the alleged "experience of pain".

As Smart in effect observes, the identity theorist is not claiming that the unpleasant disturbance in the elbow-a particular pain-as-object, we can call it - is identical to an instance of C-fiber stimulation. (That would be like identifying the yellowish-orange after-image with a brain-process.) Rather, the identity theorist is identifying a certain mental event, one's experience of pain, with an instance of C-fiber stimulation. Too bad for the identity theory, if there are no such mental events. But of course this only requires a minor adjustment: the (type-type) identity theorist should be identifying the property of seeming to be aware of pain-as-object with the property of having stimulated C-fibers.

Still, the identity theorists didn't make that adjustment. They thought that there is a type of mental event, the "experience of pain" - identical, in their view, with a certain type of neural event. It is not hard to explain why the identity theorists took the existence of such a mental event type for granted: they were heirs to a long tradition of failing to recognize pains-as-objects, and thus they conceived of pain as a mere sensation or affectation of the mind. And since something certainly seems to be going on, or happening, when one is in pain, this occurrence must be a token "experience" of pain.

Suppose the above points are right, and return to Argument $\mathrm{K}^{*}$. When we find its first premise plausible, what do we find plausible, exactly? We think that a certain event, the stimulation of C-fibers, could have occurred in the absence of another event, a "pain". That is, we think that the stimulation of C-fibers could have occurred without pain-as-object occurring. But the identity theorist-with or without the adjustment of two paragraphs back-is not identifying C-fiber stimulation with pain-as-object. Either he is identifying C-fiber stimulation with the mythical "experience of pain" or, more sensibly, is identifying the property of 
having stimulated C-fibers with the property of seeming to be aware of pain-asobject. Either way, the possibility of $\mathrm{C}$-fiber stimulation without pain-as-object is just irrelevant.

Argument $\mathrm{K}^{*}$, as traditionally understood, is doubly defective. First, it attacks the wrong form of the identity theory - the original version that identifies C-fiber stimulation with the experience of pain. Second, by the lights of such an identity theorist, it suffers from "proposition confusion": the apparently possible situation has been misdescribed as one in which there is C-fiber stimulation but no experience of pain.

Let us rewrite Argument $\mathrm{K}^{*}$ so that it at least is directed on the right target:

\section{Argument $\mathrm{K}^{* *}$}

$1^{* *}$. One could have stimulated C-fibers without being in pain (that is, without seeming to be aware of pain-as-object).

$2^{* *}$. If one could have stimulated $\mathrm{C}$-fibers without being in pain, being in pain is not identical to having stimulated C-fibers.

$3^{* *}$. Being in pain is not identical to having stimulated C-fibers.

When Kripke claims that the "the stimulation could exist without the pain" (1980: 154), he presumably has in mind a situation in which (in our terminology) there is C-fiber stimulation without pain-as-object. And the possibility of such a situation is, of course, consistent with the falsity of premise $1^{* *}$. If premise $1^{* *}$ is to be supported, there must be some other "apparent contingency": specifically, between having stimulated C-fibers and seeming to be aware of pain-as-object. Is there? One reason for suspicion is that only the first apparent contingency is clearly discernable in the literature: if there is a second apparent contingency it is has been strikingly conflated with the first. Another is more theoretical: the point of pain perception is to acquaint us with pains-as-objects, those distinctive unpleasant disturbances in our bodies; it is not to acquaint us with pain perception itself. Pains-as-objects are events that we would be expected to have some interesting modal opinions about, as we do about other familiar perceptible things like presidents and tables. The means by which we know about pains as objects is a different matter entirely; one should not expect us to have interesting modal opinions about that. Could one be aware (or seem to be aware) of pains-as-objects without having firing C-fibers, or vice versa? At the very least, a positive answer requires careful defense.

Finally, it can hardly have escaped notice that (for all this paper has argued), Kripke does have an apparently cogent argument against identifying pains-as-objects with types of physical events. Such-and-such physical whatnots in the elbow could be merrily firing away without that distinctive kind of disturbance occuring, or so we are inclined to think. Hence pain-as-objects are not firings of physical whatnots. Whether this argument succeeds is something that will be left hanging. ${ }^{26}$ 


\section{Notes}

*Many thanks to Lauren Ashwell and Tyler Doggett who commented on this paper at, respectively, a conference at MIT and the 2007 Pacific APA; thanks also to the audiences on those occasions. I am especially grateful to Steve Yablo for many helpful conversations.

1. See, e.g., Williams 1978: ch. 4, Yablo 1990, Gendler and Hawthorne 2002: 1326. In the Meditations there are two hints of the modern sort of conceivability argument. The first is in the automata passage in the Second Meditation, and second is in the Sixth, where Descartes "consider[s] the body of a man ... [with] no mind in it" (Descartes 1642/1984: 58). (Thanks here to Lauren Ashwell and Rae Langton.)

2. According to the Textbook Kripkean, "A thinker who (mistakenly) conceives $E$ as possible is correctly registering the possibility of something, and mistaking the possibility of that for the possibility of $E^{\prime \prime}(2000: 99)$. This is in one way weaker and in another way stronger than the standard interpretation under discussion. Weaker, because it is left open what "correctly registering the possibility of something" amounts to; in particular, whether it involves imagination. Stronger, because the Textbook Kripkean thinks that conceiving $E$ as possible entails the possibility of a related proposition (which may or may not be $E$ ). Yablo is careful not to label Kripke as a Textbook Kripkean (100; see also 2006: 328).

3. A "“counterfactual situation' could be thought of as a miniworld or ministate, restricted to features of the world relevant to the problem at hand" (Kripke 1980: 18); equivalently, counterfactual situations are classes of merely possible worlds.

4. Here I am indebted to Tyler Doggett.

5. It is worth noting that Kripke's use of the subjunctive- "could have been pains without brain states" - is hardly apropos, on the standard interpretation, which has us imagining that there are pains without brain states.

6. As Hart suggests (1988: 34).

7. Whether $p$ 's unimaginability is a guide to $p$ 's impossibility will not be explicitly discussed here.

8. Since there are infinitely many propositions, the interpretation of 'generally' is somewhat fraught. This paper assumes, incidentally, there are (many) impossible propositions. On the conception of a proposition as a set of possible worlds, there is one impossible proposition (the empty set) and no one believes that. (For recent discussion of this relevant to some of the present issues see Soames 2006 and Stalnaker 2006: 289-94.) On this view, believability (in the sense of "capable of being believed") entails possibility.

9. For simplicity, foisting on Kripke "the apparatus of "propositions"” (cf. Kripke 1980: 21).

10. Following tradition, 'C-fiber stimulation' should be read as a placeholder for something more plausible. Real-life C-fibers transmit signals from noxious stimuli in the body to the spinal cord.

11. See also Hill 1997; for criticism, see Yablo 2006: 328-9.

12. According to Yablo, "whoever finds $p$ conceivable enjoys something worth describing as the appearance that it is possible...conceiving involves the appearance of possibility" (1993: 5). From the perspective of this paper Yablo's talk of conceivability can be interpreted roughly as follows: I find $p$ conceivable 


\section{2 / Alex Byrne}

(equivalently "conceive $p$ " $(5, \mathrm{fn} .12)$ just in case when I imagine $p, p$ strikes me (somehow in an accredited way) as possible. On this interpretation, conceivability can be a guide to possibility consistently with Kripkean impossibilities being imaginable, even if one knows the relevant empirical facts. However, Yablo's own view is not quite so irenic, because he claims that we cannot imagine "tigers with more salt in their stomachs than sodium chloride" (30) (given we know that salt is sodium chloride). For reasons of space further discussion will have to be deferred. It is worth noting that Yablo's painstaking defense of conceivability as a guide does not depend on the assumption that Kripkean possibilities are unimaginable.

13. In fact this is what Chalmers calls 'ideal negative conceivability' (Chalmers 2002: 147).

14. Hence also ignored is Chalmers' subsequent reformulation of positive conceivability as "coherent" modal imaginability, which is a hybrid of negative conceivability and his first formulation of positive conceivability (Chalmers 2002: 153). Chalmers subjects this reformulation to a two-dimensionalist treatment. On two-dimensionalism see Chalmers 2002 and, e.g., Yablo 2002, Chalmers 2004, García-Carpintero and Maciá 2006.

15. Discussing Descartes' argument that the mind and body are distinct, Kripke says that a "plainly inadmissable" response is to accept "the Cartesian premise while denying the Cartesian conclusion" (1980: 145). The "Cartesian premise" is "that mind could exist without the body" (or conversely) (144-5), which corresponds to the first premise of Argument $\mathrm{K}^{*}$. This suggests that if the standard interpretation is correct, and Kripke is running some sort of conceivability argument, then he has the perceptual analogy in mind. But it also suggests that the standard interpretation is incorrect, since Kripke is otherwise being unhelpfully inexplicit. (Thanks here to Lauren Ashwell.)

16. See Segal 1972.

17. For the debate over olfactory imagery, see Stevenson and Case 2005.

18. See Kosslyn et al. 2006. (That book also defends a view that is not received, namely that the visual representations underlying imagery are pictorial - see the following paragraph and note.) For two ways of resisting the received view see McGinn 2004 and Martin 2002. According to McGinn, visualizing and seeing are "genuine instances of a more general notion", but are (in a way contrary to the received view), "fundamentally different" (2004: 3); according to Martin, to visualize an F is to imagine seeing an F (2002: 404).

19. See, in particular, Block 1983, Tye 1991, Pylyshyn 2002, Kosslyn et al. 2006.

20. On the latter, see Sorensen 2002: 360-1.

21. Modulo the debate over "two-dimensionalism": see note 14 above.

22. For two opposing positions see Kosslyn et al. 2006 and Pylyshyn 2003.

23. 'Sensory core' is borrowed from Martin 2002: 403.

24. For a related point, see Hart 1988: 15.

25. Since there are no after-images (no yellow-orange patch when one seems to see such an after-image), seeming to see a yellowish after-image is a kind of "hallucination"- a notoriously problematic category for theories of perception (see, e.g., Johnston 2004). Fortunately the nature of hallucinations can be ignored here.

26. And it is not confined to pain: for parallels in the case of color and color perception see Byrne 2006. 


\section{References}

Bealer, G. 2002. Modal epistemology and the rationalist renaissance. Conceivability and Possibility, ed. T. S. Gendler and J. Hawthorne. Oxford Oxford University Press.

Block, N. 1983. Mental pictures and cognitive science. Philosophical Review 93: 499-542.

Byrne, A. 2006. Color and the mind-body problem. Dialectica 60: 223-44. . forthcoming. Experience and content. Philosophical Quarterly.

Chalmers, D. J. 1996. The Conscious Mind: In Search of a Fundamental Theory. Oxford: Oxford University Press.

2002. Does conceivability entail possibility? Conceivability and Possibility, ed. T. S. Gendler and J. Hawthorne. Oxford: Oxford University Press.

2004. Epistemic two-dimensional semantics. Philosophical Studies 118: 153-226.

Descartes, R. 1642/1984. Meditations on First Philosophy. The Philosophical Writings of Descartes, ed. J. Cottingham, R. Stoorthoff and D. Murdoch. Cambridge: Cambridge University Press.

García-Carpintero, M., and J. Maciá. (eds.) 2006. Two Dimensional Semantics. Oxford: Oxford University Press.

Gendler, T. S., and J. Hawthorne. (eds.) 2002. Conceivability and Possibility. Oxford: Oxford University Press.

Hart, W. D. 1988. The Engines of the Soul. Cambridge: Cambridge University Press.

Hill, C. 1997. Imaginability, conceivability, possibility, and the mind-body problem. Philosophical Studies 87: 61-85.

Hume, D. 1740/1978. A Treatise of Human Nature. Edited by L. A. Selby-Bigge. Oxford: Oxford University Press.

Johnston, M. 2004. The obscure object of hallucination. Philosophical Studies 120: 113-87.

Kosslyn, S. M., W. L. Thompson, and G. Ganis. 2006. The Case for Mental Imagery. Oxford: Oxford University Press.

Kripke, S. 1977. Identity and necessity. Naming, Necessity, and Natural Kinds, ed. S. P. Schwartz. Ithaca: Cornell University Press.

Kripke, S. A. 1980. Naming and Necessity. Oxford: Basil Blackwell.

Martin, M. G. F. 2002. The transparency of experience. Mind and Language 17: 376-425.

McGinn, C. 2004. Mindsight: Image, Dream, Meaning. Cambridge, MA: Harvard University Press.

Nagel, T. 1974. What is it like to be a bat? Philosophical Review 83: 435-50.

Pylyshyn, Z. 2002. Mental imagery: In search of a theory. The Behavioral and Brain Sciences 25: $157-82$.

2003. Seeing and Visualizing: it's not what you think. Cambridge, MA: MIT Press.

Segal, S. J. 1972. Assimilation of a stimulus in the construction of an image: the Perky effect revisited. The Function and Nature of Imagery, ed. P. W. Sheehan. New York: Academic Press.

Smart, J. J. C. 1959. Sensations and brain processes. Philosophical Review 68: 141-56.

Soames, S. 2006. Understanding assertion. Content and Modality: themes from the philosophy of Robert Stalnaker, ed. J. Thomson and A. Byrne. Oxford: Oxford University Press.

Sorensen, R. 2002. The art of the impossible. Conceivability and Possibility, ed. T. S. Gendler and J. Hawthorne. Oxford: Oxford University Press.

Stalnaker, R. 2006. Responses. Content and Modality: themes from the philosophy of Robert Stalnaker, ed. J. Thomson and A. Byrne. Oxford:. Oxford University Press.

Stevenson, R. J., and T. I. Case. 2005. Olfactory imagery: a review. Psychonomic Bulletin \& Review 12: 244-64.

Stoljar, D. 2006. Ignorance and Imagination. Oxford: Oxford University Press.

Tidman, P. 1994. Conceivability as a test for possibility. American Philosophical Quarterly 31: 297-309. 


\section{4 / Alex Byrne}

Tye, M. 1991. The Imagery Debate. Cambridge, MA: MIT Press. 2003. Consciousness and Persons: unity and identity. Cambridge, MA: MIT Press.

Van Cleve, J. 1983. Conceivability and the cartesian argument for dualism. Pacific Philosophical Quarterly 64: 35-45.

Williams, B. 1978. Descartes: the project of pure enquiry. Harmondsworth, England: Penguin Books.

Wittgenstein, L. 1969. The Blue and Brown Books. Oxford: Basil Blackwell.

Yablo, S. 1990. The real distinction between mind and body. Canadian Journal of Philosophy supp. vol. 16: 149-201.

1993. Is conceivability a guide to possibility? Philosophy and Phenomenological Research 53: $1-42$.

2000. Textbook Kripkeanism \& the open texture of concepts. Pacific Philosophical Quarterly 81: 98-122.

2002. Coulda, woulda, shoulda. Conceivability and Possibility, ed. T. S. Gendler and J. Hawthorne. Oxford Oxford University Press.

2006. No fool's cold: notes on illusions of possibility. Two Dimensional Semantics, ed. M. García-Carpintero and J. Maciá. Oxford: Oxford University Press. 